\title{
MITRE VS. MITRE
}

MITRE VS. MITRE

PABLO GERCHUNOFF .

Profesor Emérito de la Universidad Torcuato Di Tella (Argentina).

Estamos en presencia de una gran obra. En mi opinión estamos en presencia de la biografía política e intelectual definitiva de Bartolomé Mitre, a la que sólo le ha faltado poner el foco también sobre las idas y vueltas, las luces y las sombras del ser humano. Bien escrita, gran factura, fruto sin lugar a dudas de un esfuerzo enorme y de mucha adrenalina imagino que salpicada, como siempre que se escribe, de momentos de desaliento. Quiero felicitar a Eduardo Míguez y manifestarle antes que nada mi envidia. Dicho esto, quiero además confesar que le he dado vueltas a la cuestión de cómo comentar

\section{Registro bibliográfico}

GERCHUNOFF, PABLO «Mitre vs. Mitre», en: ESTUDIOS SOCIALES, revista universitaria semestral, año XXIX, $n^{\circ} 56$, Santa Fe, Argentina, Universidad Nacional del Litoral, enero-junio, 2019, pp. 235-240. este libro, sobre todo compartiendo impresiones con Hilda Sábato y Natalio Botana. Finalmente, se me ocurrió que el mejor homenaje que le podía hacer a Míguez era recortar un tema de su obra tan abarcadora y escribir algo así como el bosquejo de un ensayo inspirado en la lectura del libro. Tengo el punto de partida del ensayo y tengo el núcleo del argumento. El punto de partida es una afirmación algo temeraria: Mitre y Rosas tienen trayectorias paralelas (afirmación que bien podría extenderse a Rivadavia). El núcleo del argumento es que Mitre fue el protagonista de un drama político.

\footnotetext{
Descriptores - Describers

biografía / historiografía / Eduardo Míguez / Bartolomé Mitre

biography / historiography / Eduardo Míguez / Bartolomé Mitre
}

Recibido: 28/09/2018 Aceptado: 03/12/2018 
¿Cómo puedo yo decir que Mitre y Rosas tienen trayectorias paralelas, aunque, me apresuro a decirlo, abismalmente distintas en sus sentidos políticos? Desde muchos puntos de vista la sola idea de trayectorias paralelas entre Mitre y Rosas aparece como un desafío al sentido común. El autor de la biografía de Belgrano en la que él mismo quiso verse reflejado al tiempo que ese texto le servía para darle un pasado confortable y creíble a una nación que todavía no existía, ¿cómo puede compararse en cualquier campo con el rudimentario Juan Manuel de Rosas? ¿Y cómo puede compararse con Rosas al traductor de la Divina Comedia en esa versión según Borges superior a la muy mediocre de Miguel Angel Batistessa? El José Luis Romero que en 1943 escribió en tono panegírico ese hermoso ensayo sobre Mitre publicado en el diario La Nación se revolvería en su tumba.

Y sin embargo Mitre y Rosas tienen efectivamente algo en común, algo así como una equivalencia funcional que le cabría también, como dije, a Rivadavia. Lo que tienen en común es que uno y otro comparten la convicción de que están donde están para realizar un destino: el del predominio de Buenos Aires sobre el resto de las provincias. Aparecerá entonces, afortunadamente, la primera diferencia. A Rosas eso le parecerá natural, el fruto del poder del dinero, del poder militar y de la voluntad política. Para Mitre la realización de ese destino tiene aristas más complicadas. Se ha propuesto desde que asomó su liderazgo en las jornadas de junio de 1852 nada menos que unir a la nación en la idea de la libertad. Asombroso por lo imposible, yo diría. Como ha expresado su adversario, el urquicista Alberdi, con palabras que él también cree, la causa de la provincia de Buenos Aires es la causa de la libertad, y no le faltará a Mitre por momentos una actitud no muy disimuladamente imperialista para imponerla donde fuere. Finalmente era un ser humano con sus ambiciones. Le gustaría creer, mientras pudiera, que la causa de la libertad no llegaría a buen puerto si no era bajo su propio comando. Si me permiten el anacronismo, esto tiene algún parecido con el Alfonsín del 1985-1987, el Alfonsín jaqueado día tras día por una sorda amenaza militar, que, enfrentado a su fragilidad, no creyó que pudiera haber democracia sin su liderazgo.

Y de la primera diferencia surgirá una segunda. Rosas es un caudillo nacional de facto, sin compromiso institucional, sin Constitución. Rosas es pura y generosa cooptación financiera a las provincias condimentada con el ejercicio de la violencia. Mitre, sea por su convicción nacionalista o porque la coyuntura posterior a Caseros obligaba a la transacción (transacción aún en los campos de batalla), necesitó casi permanentemente del compromiso institucional, no pudo sino tener como 
norte el pacto de una Constitución, y ello conllevaba menos libertad de acción, menos margen de maniobra, poder limitado. Tulio Halperín Donghi ha escrito en Una Nación para el desierto argentino algo que parafraseo: la titubeante línea política que Urquiza adopta... se apoya en una percepción más justa que la que parece haber alcanzado Mitre sobre las consecuencias de la constitucionalización del poder nacional. Las estipulaciones "demasiado» claramente definidas (sobre todo en lo que hace al equilibrio de las representaciones provinciales en el Congreso y en el Colegio Electoral presidencial) hacían más difícil convertir las victorias circunstanciales en hegemonía (HALPERIN DONGHI, 2005: 92). Y agregaría yo: hacían más difícil convertir la superioridad económica en superioridad política, como especulo que ingenuamente creyó Mitre.

Con estos elementos estamos en condiciones de acercarnos a la cuestión del drama. Saquemos la mejor fotografía posible de Mitre, aquella que resalte su mejor perfil, su momento de gloria. Voy a elegir una. Mitre gobernador y caudillo de la provincia de Buenos Aires a cargo de la presidencia de la Nación y seguro presidente constitucional en pocos meses. ¿Va a tener acaso un momento mejor? Ha llegado a la gobernación en mayo de I860 y a la presidencia provisoria de la Nación en diciembre de i86r. Tiene menos de cuarenta años y un poder por el momento indiscutido, aunque más no fuera por la amable y probablemente envenenada concesión de Urquiza. La pregunta es: ¿podrá el Mitre de esa fotografía sostener los platillos chinos danzando en el aire?; ¿podrá sostenerse como caudillo de su provincia mientras ejerce la presidencia de la nación en ciernes?; ¿podrá mantener su circo de dos pistas con ambas pistas activas?

La pregunta parece no tener sentido. ¿Por qué no podría?; ¿no retroalimenta un poder al otro?; ¿̨no es mejor tener más poder que menos poder? Y sin embargo la tensión era insalvable. Mitre no fue un presidente cualquiera justamente porque no venía de una provincia cualquiera. Venía de la provincia que a los efectos de la construcción de un Estado nacional que él mismo liderará, era la que tenía que ceder. Apelando a un segundo anacronismo, Mitre fue algo así como un catalán en el gobierno de España. Eso implica la erosión del caudillo territorial. Cuanto más eficaz y contundente fuera su liderazgo nacional en el asentamiento de ese federalismo que ha nacido desigual, más se acercará al ocaso el caudillo. Mitre vs. Mitre. Ese es el presente griego que le ha dejado Urquiza y el motivo de la probable sonrisa socarrona de Rosas desde el exilio. Lo que describimos como drama no hubiera sido ni siquiera un problema menor para cualquiera de los otros trece gobernadores porque ninguno de ellos hubiera tenido que entregar nada. Al contrario, 
habrían podido favorecer a los pueblos de su propio terruño como parte misma de la construcción del Estado nacional. Por eso será finalmente Roca quien realice algunos de los sueños de Mitre.

Aun así, milagrosamente, los platillos se mantuvieron en el aire por cinco años. Tuvo a su favor una guerra ajena que moderó la tensión y permitió distribuir beneficios inesperados. La guerra de Secesión en los Estados Unidos comenzó en abril de I86I, cuando tropas confederadas se sublevaron en Carolina del Sur. Mitre ya estaba en la gobernación y estaba a punto de hacerse cargo de la presidencia provisoria. Con la guerra el precio de la lana subió porque el abastecimiento de algodón bajó. Todo pareció beneficiar a Mitre de allí en adelante. No sólo tenía talento político; le sonreía también la fortuna. Los problemas llegarían más tarde. En ese momento tenía en la provincia natal el apoyo de los estancieros, de los ejércitos de frontera y de las masas urbanas inclinadas al Partido de la Libertad, el partido que en su mente colonizaría a la Nación entera. Y pudo ganarse al mismo tiempo a buena parte de las provincias con la obra pública, sobre todo con la promesa ferrocarrilera.

Aún en ese momento inicial el gobernador Mitre tendría que ceder a favor del presidente Mitre. Y luego el caudillo Mitre tendría que ceder a favor del presidente Mitre. Y desde ese momento todavía de bonanza tendría que convencer a los suyos de que las cesiones casi permanentes valían la pena. Y tendría que vencer a veces con rudeza y a veces con astucia los impulsos localistas de sus propios comilitones y de los herederos ocultos de los federales porteños. Así va Mitre, como lo vemos tan bien narrado por Míguez, enhebrando las piezas de una construcción estatal que, llegue a buen puerto o no, es inevitable que alimente la desconfianza porteńa respecto a su figura. La nacionalización de la única aduana del país en la que fluye el dinero, la promesa de la federalización de la ciudad de Buenos Aires, la sobreactuada oferta previa de federalizar la provincia de Buenos Aires entera, el proyecto -casi una afrentade nacionalizar el Banco de la Provincia de Buenos Aires, el proyecto de Ley de Bancos Libres, que de todas maneras hubiera roto con el monopolio del Banco, la nacionalización definitiva del impuesto a las exportaciones en la precipitada reforma constitucional de I866, que para financiar la guerra del Paraguay restó fondos propios a la maquinaria política de la Provincia de Buenos Aires, para furia del ahora dominante alsinismo, y en especial de Valentín Alsina, vocero de la irritación. En todo caso, ese año de I866 será testigo del comienzo del fin de aquel Mitre dominante en la escena provincial y nacional. En mayo Adolfo Alsina se hará de la gobernación y comenzará su propio experimento en la búsqueda siempre zig- 
zagueante y complicada de un lugar por todos consentido para Buenos Aires en la Nación. En septiembre, Curupaití dejó grabado que las palabras triunfalistas de Mitre habían sido solo bravatas y que la Guerra del Paraguay iba a ser una dura derrota política de la que Mitre no regresaría a pesar de sus esfuerzos periódicos en los largos años que restaban de su larga vida. Y eso no fue todo. La Guerra de Secesión había terminado y los precios de la lana cayeron. Fue poco después que los propietarios de la tierra de su provincia fundaron la Sociedad Rural Argentina apuntando al provechoso objetivo -que Mitre razonablemente concedió- de desvalorizar la moneda para preservar la rentabilidad. Los últimos dos años de gobierno fueron entonces difíciles. Mitre intentaría vanamente imponer a su canciller Rufino de Elizalde como su sucesor, pero se internó en el pantano político cuando percibió que eso era inalcanzable y que ni siquiera podría hacer propia la candidatura de su ministro Sarmiento.

La pregunta ahora es: ¿podría haber completado Mitre un salto mortal?; ¿podría haberse convertido en un líder nacional habiendo perdido su base territorial? Es seguro que Mitre lo intentó. Quiso imponerse sobre la República aun cuando pisaba ya un suelo fangoso en su propio terruño. Pero imponerse sobre la República, como también lo había intentado Rosas, era una tarea imposible por razones estructurales y por razones coyunturales. Las razones estructurales -ancladas en esa formidable desigualdad material entre las provincias y regiones que ni siquiera Roca pudo superar sino apenas apaciguar- están deslumbrantemente descriptas en Las guerras civiles argentinas y en El problema de Buenos Aires en la República, de Juan Álvarez. Si le creemos a Juan Alvarez, Mitre nunca hubiera podido vencer a la dictadura de la geografía, más todavía cuando el tendido ferroviario era todavía un acto de fe, la Nación que se formaba era mezquina en ríos y en puertos naturales y el proteccionismo moderado que el propio Mitre abrazaba constituía sólo un paliativo para la desigualdad. A eso se sumaron las razones coyunturales. $\mathrm{Si}$ atendemos al texto de Míguez, la participación de la República en la guerra del Paraguay fue por un lado inevitable, pero por otro lado el origen de una profunda fractura interior, especialmente intensa en el occidente andino pero que se hizo notar incluso en la provincia de Buenos Aires. En ese contexto, no había futuro para el Partido de la Libertad, ya sólo una facción sin nombre que se diluía.

Y si no pudo dar ese salto mortal que lo convirtiera en un líder nacional sin territorio, ¿̇intentó recuperar el territorio? Lo intentó por la vía del comicio y, cuando eso fracasó, impugnó los resultados electorales en la provincia de Buenos Aires por la vía de la oscura revolución armada 
de septiembre de 1874, que Míguez narra con detalle y talento (MíGUEZ, 2OII). Y por esa vía también fracasó. Ese fue el fin de un ciclo, el drama que se consuma. Las últimas cincuenta y cinco páginas del libro de Míguez, el capítulo nueve, llevan como título «La construcción de un prócer». Son palabras sugerentes. Un prócer vivo puede participar de la vida pública pero el carácter de su intervención ya no es el de un político que lucha por el poder. Puede ser persuasivo, puede tener influencia moral, como en I890 y I89I, pero no tendrá el poder ni cambiará el destino de la nación entera. Sus triunfos y sus derrotas serán de otra naturaleza
(MíGuez, 20I8: 385-43I). En ese sentido quiero contarles para terminar, algo que es un hallazgo historiográfico que le regalo a Míguez para la segunda edición de su biografía: me refiero al último triunfo que le conozco a Mitre. Hace menos de un mes, después de ascender al Torneo Nacional в, el equipo de Platense jugó su primer partido en la nueva categoría en carácter de local. Fue el domingo 26 de agosto de 2018 a las 15:30 hs. y perdió. El ganador fue... Mitre de Santiago del Estero. Yo, vecino de la zona, vi a los fantasmas de los hermanos Taboada y del propio general festejar en el atardecer de la Avenida Zufriategui.

\section{Referencias bibliográficas}

HALPERIN DONGHI, TULIO (2005): Una nación para el desierto argentino, Buenos Aires, Prometeo. MÍGUEZ, EDUARDO (2011): Mitre montonero. La Revolución de 1874 y las formas de la política en la organización nacional, Buenos Aires, Sudamericana.

MÍGUEZ, EDUARDO (2018): Bartolomé Mitre. Entre la nación y la historia, Buenos Aires, Edhasa. 